\title{
Gene expression profiling reveals novel TGF $\beta$ targets in adult lung fibroblasts
}

\author{
Elisabetta A Renzoni', David J Abraham², Sarah Howat ${ }^{3}$, Xu Shi-Wen², \\ Piersante Sestini ${ }^{4}$, George Bou-Gharios ${ }^{5}$, Athol U Wells ${ }^{1}$, \\ Srihari Veeraraghavan ${ }^{1}$, Andrew G Nicholson ${ }^{6}$, Christopher P Denton ${ }^{2}$, \\ Andrew Leask ${ }^{2}$, Jeremy D Pearson ${ }^{3}$, Carol M Black ${ }^{2}$, Kenneth I Welsh ${ }^{1}$ and \\ Roland $\mathrm{M}$ du Bois*1
}

\begin{abstract}
Address: ${ }^{1}$ Interstitial Lung Disease Unit, Royal Brompton Hospital, Imperial College of Science, Technology and Medicine, Emmanuel Kaye Building, 1B Manresa Road, SW3 6LR, London, UK, ${ }^{2}$ Division of Academic Rheumatology, Royal Free Hospital, London, U.K, ${ }^{3}$ Centre for Cardiovascular Biology and Medicine, Guy's, King's, and St. Thomas' School of Biomedical Sciences, King's College London, UK, ${ }^{4}$ Division of Respiratory Diseases, University of Siena, Siena, Italy, ${ }^{5} \mathrm{MRC}$ Clinical Science Centre, Hammersmith Campus, Imperial College London, UK and ${ }^{6}$ Dept of Pathology, Royal Brompton Hospital, London, UK

Email: Elisabetta A Renzoni - e.renzoni@imperial.ac.uk; David J Abraham - d.abraham@rfc.ucl.ac.uk; Sarah Howat - sarah.howat@kcl.ac.uk; Xu Shi-Wen - shiwen@rfc.ucl.ac.uk; Piersante Sestini - sestini@unisi.it; George Bou-Gharios - e.renzoni@imperial.ac.uk; Athol U Wells - a.wells@rbh.nthames.nhs.uk; Srihari Veeraraghavan - srihari1@yahoo.com;

Andrew G Nicholson - a.nicholson@rbh.nthames.nhs.uk; Christopher P Denton - c.denton@rfc.ucl.ac.uk; Andrew Leask - a.leask@rfc.ucl.ac.uk; Jeremy D Pearson - jeremy.pearson@kcl.ac.uk; Carol M Black - c.black@rfc.ucl.ac.uk; Kenneth I Welsh - k.welsh@imperial.ac.uk; Roland M du Bois* - R.DuBois@rbh.nthames.nhs.uk

* Corresponding author
\end{abstract}

Published: 30 November 2004

Respiratory Research 2004, 5:24 doi:10.1 186/1465-9921-5-24

This article is available from: http://respiratory-research.com/content/5/I/24

(C) 2004 Renzoni et al; licensee BioMed Central Ltd.

This is an Open Access article distributed under the terms of the Creative Commons Attribution License (http://creativecommons.org/licenses/by/2.0), which permits unrestricted use, distribution, and reproduction in any medium, provided the original work is properly cited.
Received: 05 September 2004

Accepted: 30 November 2004

\begin{abstract}
Background: Transforming growth factor beta (TGF $\beta$ ), a multifunctional cytokine, plays a crucial role in the accumulation of extracellular matrix components in lung fibrosis, where lung fibroblasts are considered to play a major role. Even though the effects of TGF $\beta$ on the gene expression of several proteins have been investigated in several lung fibroblast cell lines, the global pattern of response to this cytokine in adult lung fibroblasts is still unknown.

Methods: We used Affymetrix oligonucleotide microarrays U95v2, containing approximately 12,000 human genes, to study the transcriptional profile in response to a four hour treatment with TGF $\beta$ in control lung fibroblasts and in fibroblasts from patients with idiopathic and sclerodermaassociated pulmonary fibrosis. A combination of the Affymetrix change algorithm (Microarray Suite 5 ) and of analysis of variance models was used to identify TGF $\beta$-regulated genes. Additional criteria were an average up- or down- regulation of at least two fold.

Results: Exposure of fibroblasts to TGF $\beta$ had a profound impact on gene expression, resulting in regulation of 129 transcripts. We focused on genes not previously found to be regulated by TGF $\beta$ in lung fibroblasts or other cell types, including nuclear co-repressor 2, SMAD specific E3 ubiquitin protein ligase 2 (SMURF2), bone morphogenetic protein 4, and angiotensin II receptor type I (AGTRI), and confirmed the microarray results by real time-PCR. Western Blotting confirmed induction at
\end{abstract}


the protein level of AGTRI, the most highly induced gene in both control and fibrotic lung fibroblasts among genes encoding for signal transduction molecules.

Upregulation of AGTRI occurred through the MKKI/MKK2 signalling pathway. Immunohistochemical staining showed AGTRI expression by lung fibroblasts in fibroblastic foci within biopsies of idiopathic pulmonary fibrosis.

Conclusions: This study identifies several novel TGF $\beta$ targets in lung fibroblasts, and confirms with independent methods the induction of angiotensin II receptor type I, underlining a potential role for angiotensin II receptor I antagonism in the treatment of lung fibrosis.

\section{Background}

Transforming Growth Factor beta (TGF $\beta$ ) is a multifunctional cytokine that regulates a variety of physiological processes, including cell growth and differentiation, extracellular matrix production, embryonic development and wound healing [1]. Altered expression of TGF $\beta$ plays a crucial role in organ fibrosis, hypertrophic scarring, cancer, autoimmune and inflammatory diseases [2].

In the lung, TGF $\beta$ is consistently linked with progressive fibrosis [3-5]. Increased expression of TGF $\beta$ has been reported in a variety of fibrotic lung diseases $[6,7,3]$, including idiopathic pulmonary fibrosis (IPF), a relentlessly progressive fibrotic lung disease with a median survival from diagnosis of only two years [8], and pulmonary fibrosis associated with systemic sclerosis, one of the leading causes of death in scleroderma patients [9]. Animal models also support a central role played by TGF $\beta$ in lung fibrosis. Intra-tracheal adenovirus-mediated TGF $\beta$ gene transfer causes severe lung fibrosis extending to the periphery of the lungs [5]. Mice lacking alphavbeta 6, an integrin which is crucial to the release of active TGF $\beta$ from latent extracellular complexes, develop lung inflammation but are strikingly protected from bleomycin-induced lung fibrosis [10]. IL-13 overexpression induces lung fibrosis which is mediated via TGF- $\beta 1$ induction and activation [11]. Experimental inhibition of TGF $\beta$ with neutralizing antibodies, soluble receptors, or gene transfer of the TGF $\beta$ inhibitor Smad7, inhibits fibrosis in animal models [12-14].

Lung fibroblasts are the main cell type responsible for excessive extracellular matrix synthesis and deposition in fibrosing lung disorders [15]. TGF $\beta$ modulates fibroblast function through several mechanisms, including induction of extracellular matrix protein synthesis and inhibition of collagen degradation [1]. However, knowledge of TGF $\beta$ targets in adult lung fibroblasts is still limited to a small number of genes. Oligonucleotide array technology allows the simultaneous assessment of thousands of genes providing a global gene expression profiling of the response to a stimulus. The response to TGF $\beta$ has been investigated using oligonucleotide microarrays in kerati- nocytes [16] as well as in dermal [17] and in a human fetal lung fibroblast line [18], but not in primary human adult lung fibroblasts. Fibroblastic responses are likely to vary with the origin and developmental state of the cells [19], and a detailed study of TGF $\beta$ responses in adult lung fibroblasts is needed to gain further insights into the fibroproliferative process in the lung.

We therefore quantified gene expression by oligonucleotide microarrays of adult lung fibroblasts (derived from biopsies of normal and both idiopathic and sclerodermaassociated pulmonary fibrosis) in response to TGF $\beta$, and identified several novel TGF $\beta$ targets among the wide variety of genes regulated by this cytokine. Of these, we particularly focused on angiotensin II receptor type 1, the most highly TGF $\beta$-induced gene among those encoding for signal transduction molecules.

\section{Methods \\ Cell culture}

Primary adult lung fibroblasts were cultured from three control samples (unaffected lung from patients undergoing cancer-resection surgery) and from open-lung biopsy samples of lung fibrosis patients, three with idiopathic pulmonary fibrosis (IPF) [8] and three with pulmonary fibrosis associated with the fibrotic disease systemic sclerosis [9]. Independent reviews of the clinical (SV, ER) and histopathologic diagnosis (AGN) were performed. All the idiopathic pulmonary fibrosis biopsies were characterized by a usual interstitial pneumonia pattern (UIP), whereas all of the scleroderma-associated pulmonary fibrosis were classified as non-specific interstitial pneumonia (NSIP) [8]. Verbal and written consent was given by all subjects; authorization was given by the Royal Brompton Hospital Ethics Committee. Fibroblast culture conditions were as previously described [20]. At confluence, lung fibroblasts (all between passages 4-5) were serum-deprived for 16 hours, and exposed to either $4 \mathrm{ng} / \mathrm{ml}$ of activated TGF- $\beta 1$ (R\&D Systems) or serum-free culture medium for four hours. The concentration and time point of TGF $\beta$ used in our experiments was determined from ongoing studies within our laboratory, in which a 4 hour treatment with 
TGF $\beta 4 \mathrm{ng} / \mathrm{ml}$ was found to show significant induction of selected known direct TGF $\beta$ target genes, including CTGF.

\section{RNA isolation and gene array analysis}

At the end of the treatment period with or without TGF $\beta$, total RNA was harvested (Trizol, Life Technologies), quantified, and integrity was verified by denaturing gel electrophoresis.

Preparation of RNA samples for chip hybridization followed Affymetrix (Affymetrix, Santa Clara, California) protocols. Each RNA sample derived from an individual fibroblast line was hybridized on a separate microarray chip. Hybridization of cRNA to Affymetrix human U95Av2 chips, containing approximately 12,000 well characterized human genes, signal amplification and data collection were performed using an Affymetrix fluidics station and chip reader, following Affymetrix protocol. Scanned files were analyzed using Affymetrix Version 5.0 software (MAS5). Chip files were analyzed by scaling to an average intensity of 150 per gene, as recommended by Affymetrix. Reproducibility was assessed using two pairs of RNA samples from the same control line, TGF $\beta$-treated/ untreated; the concordance correlation coefficients were of 0.979 and 0.983 , respectively.

TGF $\beta$ response was analyzed by using a combination of the MAS5 Affymetrix change algorithm and of ANOVA models. According to Affymetrix criteria, in each TGF $\beta$ treated/medium only pair, genes were defined as differentially regulated (either up or down) by TGF $\beta$ only when identified as significantly increased (I) or decreased (D) as determined by the Affymetrix change algorithm, with a change $p$ value $<0.001$, and were detected as Present (according to the "absolute call"obtained by an Affymetrix algorithm) at least in the samples with the highest count (i.e. medium only in the case of D and TGF $\beta$ in the case of I). Genes were defined as TGF $\beta$-responsive in normal human lung fibroblasts when they fulfilled all of the following three conditions: a) they were detected as TGF $\beta$ regulated by Affymetrix criteria (see above) in at least two of the three control pairs; b) they showed a mean fold change after TGF $\beta$ of at least 2 (or lower than 0.5) in control fibroblasts; $c$ ) either a two-way ANOVA including only control fibroblasts detected a significant $(\mathrm{p}<0.05)$ increase or decrease in control fibroblasts after TGF $\beta$ or they were also found to be responsive in at least four of the six fibrotic fibroblast lines and a significant effect ( $\mathrm{p}<$ 0.05 ) of treatment (with TGF $\beta$ ) was detected by a repeated measure ANOVA model including all the samples and adjusting for individual samples, disease, and interaction between treatment and disease. All statistical analyses were performed on log transformed data to reduce inequalities of variance. Thus, the latter ANOVA model could detect genes which were equally up- or down-regulated in normal and fibrotic fibroblasts, taking advantage of the larger number of samples, while the first model (equivalent to a paired t test) could detect changes possibly occurring in controls but not in fibrotic cell lines.

Except for unknown genes, all gene symbols and names are given according to the nomenclature proposed by the Human Genome Organization (HUGO) Gene Nomenclature Committee.

\section{Real time-PCR}

Real time PCR (RT-PCR) was performed to confirm selected novel TGF $\beta$ targets in lung fibroblasts. Adult lung fibroblast lines [three control and three fibrotic (IPF)] were treated with or without TGF $\beta(4 \mathrm{ng} / \mathrm{ml})$ for four hours. Total RNA was isolated from treated and untreated samples using Trizol (Life Technologies) and the integrity of the RNA was verified by gel electrophoresis. Total RNA ( 1 microgram) was reverse transcribed in a $20 \mu$ reaction volume containing oligonucleotide $\mathrm{dTs}\left(\mathrm{dT}_{18}\right)$ and random decamers $\left(\mathrm{dN}_{10}\right)$ using M-MLV reverse transcriptase (Promega) for 1 hour at $37^{\circ} \mathrm{C}$. The cDNA was diluted to $100 \mu \mathrm{l}$ with DEPC-treated water and $1 \mu \mathrm{l}$ was used per real-time PCR reaction. A set of eight standards containing a known concentration of target amplicon was made by PCR amplification, isolation by gel electrophoresis through a $2 \%$ agarose gel followed by gel purification using QIAquick PCR purification spin columns (Qiagen). The concentration of the amplicon was measured by spectrophotometry and diluted in DEPC-treated water containing transfer RNA $(10 \mu \mathrm{g} / \mathrm{ml})$ to make standards of 10 fold dilutions from $100 \mathrm{pg} / \mu \mathrm{l}$ to $0.01 \mathrm{fg} / \mu \mathrm{l}$. The target was measured in each sample and standard by real-time PCR using FastStart DNA Master SYBR Green (Roche Applied Science) as described by the manufacturer, in half the reaction volume $(10 \mu \mathrm{l})$. Samples and standards were amplified for 30 to 40 cycles with the appropriate primers (Molecular Biology Unit, KCL School of Biological Sciences) at least in duplicate. The amount of target in the sample in picograms was read from the standard curve and values were normalised to $28 \mathrm{~S}$ ribosomal RNA (pg of target/pg of $28 \mathrm{~S}$ ribosomal-RNA). The oligonucleotide primer sequences are listed (5'-3'): angiotensin II receptor type1 (AGTR1) primers: forward TGC TTC AGC CAG CGT CAG TT and reverse GGG ACT CAT AAT GGA AAG CAC; SMAD specific E3 ubiquitin protein ligase 2 (SMURF2): forward AAC AAG AAC TAC GCA ATG GGG and reverse GTC CTC TGT TCA TAG CCT TCT G; nuclear receptor co-repressor 2 (NCOR2): forward CAG CAG CGC ATC AAG TTC AT and reverse GTA ATA GAG GAC GCA CTC AGC; bone morphogenetic protein 4 (BMP4) primers: forward CTA CTG GAC ACG AGA CTG GT and reverse GAG TCT GAT GGA GGT GAG TC. 
The results were analyzed using Student's paired t-test after logarithmic transformation, and statistical significance was taken as a p value of $<0.05$.

\section{Western blot analysis of TGF $\beta$-induction of angiotensin II receptor I}

Lung fibroblasts were grown to confluence in DMEM with $10 \%$ FCS. At confluence, lung fibroblasts (all between passages 2-5) were serum-deprived overnight, and exposed to either $4 \mathrm{ng} / \mathrm{ml}$ of activated TGF- $\beta 1$ (R\&D Systems) or serum-free culture-medium with the addition of $0.1 \%$ BSA for 24 hours. To determine the signalling pathways through which TGF $\beta$ induces AGTR1, lung fibroblasts were treated with specific inhibitors 30 minutes before treatment with TGF $\beta$. These included the dual MKK1/MKK2 inhibitor U0126 (10 $\mu \mathrm{M})$ and predominant MKK1 inhibitor PD98059 (50 $\mu \mathrm{M})$, known to inhibit MKK2 only weakly [21], as well as the p38 MAPK inhibitor SB $202190(30 \mu \mathrm{M})$. Cell layer lysates were examined. Cell protein $(10 \mu \mathrm{g} / \mathrm{sample})$ was heated to $99^{\circ} \mathrm{C}$ for 5 min, loaded into sample wells, resolved on a $12 \%$ tricine SDS-polyacrylamide gel (Novex, San Diego, CA), and run at $120 \mathrm{~V}$ for $2 \mathrm{~h}$. The separated proteins were transferred onto nitrocellulose membranes at $30 \mathrm{~V}$ for 90 minutes. Membranes were blocked by incubation for one hour with 5\% non-fat milk in phosphate buffered saline (PBS) containing $0.1 \%$ Tween 20 . They were then washed and incubated overnight at $4^{\circ} \mathrm{C}$ in a $1: 500$ dilution of rabbit anti-angiotensin II receptor 1 polyclonal antibody (Santa Cruz Biotechnology), followed by a three-time wash in PBS and incubation in 1:1000 goat anti-rabbit biotinylated IgG (Vector Laboratories, Peterborough, UK) for $60 \mathrm{~min}$ at room temperature. Membranes were washed three times in PBS, and the signal was amplified/detected by using the ECL protocol as described by the manufacturer (Amersham plc, Little Chalfont, UK). Films were analysed by laser scanning densitometry on an Ultrascan XL (LKB-Wallac, UK). Data were analyzed by using Student's paired $\mathrm{t}$ test after $\log$ transformation and a $\mathrm{p}$ value $<0.05$ was considered significant.

\section{Immunohistochemistry}

The distribution of staining for AGTR1 was assessed by immunohistochemistry in surgical lung biopsies from four patients with idiopathic pulmonary fibrosis (IPF), meeting the diagnostic criteria of the American Thoracic Society/European Respiratory Society Consensus Classification [8], and in control biopsies (normal periphery of resected cancer) from three patients undergoing cancer resection surgery. Paraffin-embedded sections were dewaxed with xylene, hydrated and heated in the microwave at 120 degrees for 30 minutes in citrate buffer (10 $\mathrm{mM}$ pH 6.0).
Slides were then briefly rinsed in PBS, blocked with 10\% normal goat serum for 20', incubated with rabbit polyclonal anti-human AGTR1 antibody (N-10, 1:50, Santa Cruz Biotechnology, Santa Cruz, Calif) for one hour at room temperature. After washing with PBS, sections were incubated with biotinylated goat anti-rabbit IgG diluted in PBS (1:200) for 30 minutes, rinsed, and finally incubated with Vectastain Elite STR-ABC reagent (Vector Laboratories) for 30 minutes. After washing, sections were visualized using 3-amino-9-ethylcarbazole chromogen and $\mathrm{H}_{2} \mathrm{O}_{2}$ as substrate (SK-4200; Vector Laboratories). Sections were then washed in tap water, counterstained with Carrazzis hematoxylin, and mounted with Gelmount (Biomeda, Foster City, CA) for examination using an Olympus BH-2 photomicroscope. Controls included an exchange of primary antibodies with goat matched antibodies. To confirm staining specificity, sections were also incubated with either nonimmune rabbit IgG control or secondary antibody only.

\section{Results \\ Microarray analysis of TGF $\beta$-response in primary adult lung fibroblasts}

According to the criteria outlined in the methods, a four hour treatment with TGF $\beta$ was found to regulate 129 transcripts in human lung fibroblasts. TGF $\beta$-responsive transcripts included genes with roles in gene expression, matrix formation, cytoskeletal remodelling, signalling, cell proliferation, protein expression and degradation, cell adhesion and metabolism. A complete list of TGF $\beta$-regulated genes is provided (see Additional file 1). The complete set of gene array data has been deposited in the Gene Expression Omnibus database with GEO serial accession number GSE1724 http://www.ncbi.nlm.nih.gov/geo.

We did not observe a substantial degree of difference in the response to TGF $\beta$ between the two fibrotic groups (idiopathic pulmonary fibrosis and scleroderma-associated pulmonary fibrosis) and control lung fibroblasts. Once the criteria outlined in the methods section and the pvalue for interaction with treatment had been taken into account, there were no significant differences in the response to TGF $\beta$ among the three groups except for two genes, KIAA0261 (probe N: 40086_at), an unknown gene more upregulated in IPF (median fold change 2.2) than in scleroderma-associated pulmonary fibrosis (1.5) and in controls (1.3), and BTG1 (probe N: 37294_at), which was only slightly more downregulated in scleroderma-associated pulmonary fibrosis (fold change:0.4) than in IPF (0.6) and in controls (0.7). As both the number of genes and the magnitude of the differences were minimal, they were not considered meaningful and were not investigated further. Among genes responding significantly to TGF $\beta$ in control lung fibroblasts, as assessed by ANOVA analysis, none changed in opposite directions in either of 
Table I: Transcription factor genes regulated by TGF $\beta$ in control and fibrotic lung fibroblasts (LF)

\begin{tabular}{|c|c|c|c|c|}
\hline Gene Symbol & $\begin{array}{l}\text { Affymetrix Probe } \\
\mathrm{N}\end{array}$ & $\begin{array}{l}\text { Control } \\
\text { LF* }\end{array}$ & $\begin{array}{l}\text { Fibrot } \\
\text { ic LF* }\end{array}$ & Gene name \\
\hline BHLHB2 & 40790_at & 6.0 & 5.1 & basic helix-loop-helix domain containing, class B, 2 \\
\hline CBFB & 4II75_at & 2.9 & 2.8 & core-binding factor, beta subunit \\
\hline EGR2 & 37863_at & 52.0 & 3.3 & early growth response 2 (Krox-20 homolog, Drosophila) \\
\hline ETV6 & 38491_at & 2.0 & 2.6 & ets variant gene 6 (TEL oncogene) \\
\hline FOXOIA & 40570_at & 3.8 & 6.0 & forkhead box OIA (rhabdomyosarcoma) \\
\hline JUNB & 2049_s_at & 3.7 & 4.2 & jun $B$ proto-oncogene \\
\hline JUNB & 32786_at & 4.4 & 3.0 & jun $B$ proto-oncogene \\
\hline LRRFIPI & $41320 \_$s_at & 2.1 & 1.5 & leucine rich repeat (in FLII) interacting protein I \\
\hline MKLI & 35629_at & 2.7 & 2.6 & megakaryoblastic leukemia (translocation) I \\
\hline MSC & 35992_at & 2.4 & 1.7 & musculin (activated B-cell factor-I) \\
\hline NCOR2 & 39358_at & 2.2 & 2.2 & nuclear receptor co-repressor 2 \\
\hline NPAS2 & 39549_at & 2.4 & 3.1 & neuronal PAS domain protein 2 \\
\hline NR2F2 & 39397_at & 0.4 & 0.5 & nuclear receptor subfamily 2 , group $F$, member 2 \\
\hline NRIPI & 40088_at & 2.3 & 1.8 & nuclear receptor interacting protein I \\
\hline RUNXI & 393_s_at & 2.3 & 2.6 & runt-related transcription factor I (amll oncogene) \\
\hline RUNXI & 3942I_at & 3.1 & 2.3 & runt-related transcription factor I (amll oncogene) \\
\hline RUNXI & 943_at & 2.2 & 2.7 & runt-related transcription factor I (amll oncogene) \\
\hline SKI & 41499_at & 2.5 & 2.1 & v-ski sarcoma viral oncogene homolog (avian) \\
\hline SMURF2 & 33354_at & 2.2 & 2.2 & E3 ubiquitin ligase SMURF2 \\
\hline SRF & 1409_at & 2.1 & 1.9 & serum response factor \\
\hline SRF & 40109_at & 2.2 & 2.0 & serum response factor \\
\hline TCF2I & 37247_at & 0.2 & 0.4 & transcription factor 21 \\
\hline TCF8 & 33439_at & 2.8 & 1.8 & transcription factor 8 (represses interleukin 2 expression) \\
\hline TIEG & 224_at & 2.2 & 2.1 & TGFB inducible early growth response \\
\hline TIEG & 38374_at & 3.2 & 2.7 & TGFB inducible early growth response \\
\hline ZFP36L2 & 32587_at & 0.3 & 0.4 & zinc finger protein $36, \mathrm{C} 3 \mathrm{H}$ type-like 2 \\
\hline ZFP36L2 & 32588_s_at & 0.3 & 0.3 & zinc finger protein $36, \mathrm{C} 3 \mathrm{H}$ type-like 2 \\
\hline ZNF365 & 35959_at & 14.2 & 2.5 & zinc finger protein 365 \\
\hline
\end{tabular}

* Mean fold change in mRNA abundance in TGF $\beta$ treated/untreated control and fibrotic lung fibroblasts (LF), respectively. Fibrotic lung fibroblast ratios represent the average values of idiopathic and scleroderma-associated pulmonary fibrosis lung fibroblasts.

the fibrotic groups. All the genes that responded significantly in the control group alone, were also TGF $\beta$-responsive when analysis was extended to include the fibrotic cell lines. Furthermore, none of these genes responded differently to TGF $\beta$ between the two fibrotic groups, which are thus presented together in Tables 1 and 2.

For the purpose of this study, we will concentrate on genes involved in transcriptional regulation, cytoskeletal/extracellular matrix organization, and signal transduction (Tables 1 and 2).

\section{Control of transcription}

TGF $\beta$ regulated a wide array of transcription factors (Table 1 ), including the known TGF $\beta$ target JUNB. Other TGF $\beta$ targets in lung fibroblasts identified by this study included Smad co-activators RUNX1 and CBFB, recently implicated in the targeted subnuclear localization of TGF $\beta$-regulated Smads $[22,23]$. Transcriptional regulators involved in cell cycle control/cell differentiation induced by TGF $\beta$ included FOXO1A, NPAS2, and TIEG (TGF $\beta$-inducible early growth response), while ZFP36L2, a zinc finger transcription factor linked to cell proliferation induction, was repressed by TGF $\beta$. Serum response factor (SRF) and MKL1 were also induced by TGF $\beta$. Transcriptional repressors induced by TGF $\beta$ included Ski, which together with Sno interacts with Smad molecules to inhibit transcription and may contribute to terminating TGF $\beta$ response [24] and TCF8, a previously reported TGF $\beta$ target in fetal lung fibroblasts [18]. Other transcriptional co-repressors upregulated by TGF $\beta$ were nuclear co-repressors NCOR2 (or SMRT) and BHLHB2, which repress transcription by recruiting histone deacetylases [25], and musculin (MSC).

\section{Cytoskeletal/Extracellular matrix organization}

Most genes in this category were known TGF $\beta$ targets. As expected, transcripts involved in promoting extracellular matrix formation and cell adhesion such as connective tissue growth factor (CTGF) were upregulated, while we observed inhibition of bone morphogenetic protein 4 (BMP4), a member of the TGF $\beta$ superfamily whose 
Table 2: TGF $\beta$-regulated signalling and ECM/cytoskeletal genes in control and fibrotic lung fibroblasts

\begin{tabular}{|c|c|c|c|c|}
\hline Gene Symbol & Affymetrix Probe $\mathrm{N}$ & Control LF* & Fibrotic LF* & Gene name \\
\hline \multicolumn{5}{|c|}{ Signal transduction } \\
\hline ACVRI & 39764_at & 2.2 & 1.7 & activin A receptor, type I \\
\hline ADM & 34777_at & 0.3 & 0.4 & adrenomedullin \\
\hline AGTRI & 346_s_at & 3.8 & 3.2 & angiotensin II receptor, type I \\
\hline AGTRI & 37983_at & 5.1 & 5.9 & angiotensin II receptor, type I \\
\hline BDKRB2 & 39310_at & 0.4 & 0.4 & bradykinin receptor B2 \\
\hline BMP4 & 1114 & 0.2 & 0.2 & bone morphogenetic protein 4 \\
\hline BMP4 & 40333_at & 0.1 & 0.3 & bone morphogenetic protein 4 \\
\hline DYRK2 & 40604_at & 3.0 & 3.0 & dual-specificity tyrosine-(Y)-phosphorylation regulated kinase 2 \\
\hline DYRK2 & 760_at & 2.9 & 3.3 & dual-specificity tyrosine-(Y)-phosphorylation regulated kinase 2 \\
\hline DYRK2 & $761 \_$g_at & 3.3 & 2.2 & dual-specificity tyrosine-(Y)-phosphorylation regulated kinase 2 \\
\hline MLP & 36174_at & 2.4 & 1.7 & MARCKS-like protein \\
\hline PLK2 & 41544_at & 0.4 & 0.6 & polo-like kinase 2 (Drosophila) \\
\hline RRAD & 1776_at & 3.0 & 5.2 & Ras-related associated with diabetes \\
\hline RRAD & 39528_at & 3.6 & 5.1 & Ras-related associated with diabetes \\
\hline SMAD3 & 38944_at & 0.4 & 0.4 & SMAD, mothers against DPP homolog 3 (Drosophila) \\
\hline SMAD7 & 1857_at & 2.3 & 2.2 & SMAD, mothers against DPP homolog 7 (Drosophila) \\
\hline SOCSI & 41592 at & 0.1 & 0.1 & suppressor of cytokine signaling I \\
\hline SPRY2 & 33700_at & 2.0 & 1.8 & sprouty homolog 2 (Drosophila) \\
\hline STK38L & 32182_at & 3.7 & 3.8 & serine/threonine kinase 38 like \\
\hline TGFBR3 & 1897_at & 0.3 & 0.5 & transforming growth factor, beta receptor III (betaglycan) \\
\hline TNFRSFIB & 1583_at & 0.4 & 0.6 & tumor necrosis factor receptor superfamily, member IB \\
\hline TNFRSFIB & 33813_at & 0.4 & 0.4 & tumor necrosis factor receptor superfamily, member IB \\
\hline TSPAN-2 & 35497_at & 4.2 & 5.0 & tetraspan 2 \\
\hline \multicolumn{5}{|c|}{ Extracellular matrix remodelling/Cytoskeletal } \\
\hline COL4AI & 39333_at & 2.2 & 2.0 & collagen, type IV, alpha I \\
\hline COMP & 40161_at & 2.7 & 5.3 & cartilage oligomeric matrix protein \\
\hline COMP & 40162_s_at & 5.0 & 18.9 & cartilage oligomeric matrix protein \\
\hline CTGF & 36638_at & 4.8 & 6.1 & connective tissue growth factor \\
\hline CYR6I & 38772_at & 4.4 & 3.5 & cysteine-rich, angiogenic inducer, 61 \\
\hline ELN & 3162I_s_at & 4.9 & 3.7 & elastin \\
\hline ELN & 39098_at & 8.4 & 11.6 & elastin \\
\hline PLAUR & 189_s_at & 2.7 & 2.8 & plasminogen activator, urokinase receptor \\
\hline PLOD2 & 34795_at & 2.5 & 1.8 & procollagen-lysine, 2-oxoglutarate 5-dioxygenase 2 \\
\hline SERPINEI & 38I25_at & 3.7 & 4.0 & serine (or cysteine) proteinase inhibitor, clade $\mathrm{E}$, member I \\
\hline SERPINEI & 672_at & 6.0 & 5.5 & serine (or cysteine) proteinase inhibitor, clade $\mathrm{E}$, member I \\
\hline TIMP3 & 1034_at & 2.0 & 1.5 & tissue inhibitor of metalloproteinase 3 \\
\hline TIMP3 & 1035_g_at & 2.4 & 1.6 & tissue inhibitor of metalloproteinase 3 \\
\hline TPMI & 36790_at & 2.3 & 1.7 & tropomyosin I (alpha) \\
\hline TPMI & 3679I_g_at & 2.7 & 2.1 & tropomyosin I (alpha) \\
\hline TPMI & 36792 at & 2.5 & 2.0 & tropomyosin I (alpha) \\
\hline
\end{tabular}

Mean fold change in mRNA abundance in TGF $\beta$ treated/untreated control and fibrotic lung fibroblasts (LF), respectively. Fibrotic lung fibroblast ratios represent the average of idiopathic and scleroderma-associated pulmonary fibrosis lung fibroblasts.

activity has recently been shown to be inhibited by CTGF through direct binding [26].

TGF $\beta$ also induced matrix genes including elastin (ELN), collagens (COL4A1), plasminogen activator inhibitor (PAI1 or SERPINE1) and PLOD2, an enzyme which stabilizes collagen cross-links (Table 2). Tissue inhibitor of matrix metalloproteinase 3 (TIMP3) was upregulated by TGF $\beta$. Genes involved in cytoskeletal organization induced by TGFß included known target tropomyosin (TPM1). Interest- ingly, smoothelin, a smooth muscle gene recently reported to be highly induced by TGF $\beta$ in fetal lung fibroblasts [18], was also induced by TGF $\beta$ in this study, but at a slightly lower fold ratio than that chosen for the selection criteria (1.8).

\section{Control of signal transduction}

Among signalling molecules (Table 2), known targets included upregulation of SMAD7 and downregulation of SMAD3 $[18,16]$. Novel targets in lung fibroblasts included 
SMURF2, a recently identified E3 ubiquitin ligase, which negatively regulates TGF $\beta$ signalling by targeting both TGF $\beta$ receptor-Smad7 complexes and Smad2 for ubiquitin-dependent degradation $[27,28]$. At the investigated timepoint, TGF $\beta$ downregulated the accessory receptor betaglycan, a membrane anchored proteoglycan which increases the affinity between TGF $\beta$ and type I and II receptors. Interestingly, TGF $\beta$ upregulated activin A type I receptor, a receptor for TGF $\beta$ family member activin, whose stimulation induces fibroblast-mediated collagen gel contraction [29]. Members of the Ras family of GTPases, ARHB and RADD (Ras-related GTP-binding protein), involved in cytoskeleton remodelling, were also upregulated by TGF $\beta$. TGF $\beta$ also induced Dickkopf1 (DKK1), a potent inhibitor of Wnt/beta-catenin signalling.

Of particular interest was the novel observation that TGF $\beta$ upregulated angiotensin II receptor 1 (AGTR1) in lung fibroblasts; conversely, the gene encoding for vasodilatory peptide adrenomedullin (ADM) was inhibited by TGF $\beta$.

\section{Validation of selected TGF $\beta$-induced genes by real time RT-PCR}

Several of the genes regulated by TGF $\beta$ confirmed previously published findings, thus validating our methods, including JUN-B, SMAD7, connective tissue growth factor, elastin, and SERPINE1 $[17,18,16,30]$. To further consolidate our analysis, we selected a small group of novel TGF $\beta$ targets to be confirmed by RT-PCR in both control and fibrotic lung fibroblasts. These novel fibroblast TGF $\beta$ responsive genes included potential key candidates in the regulation by TGF $\beta$ of lung tissue fibrosis and included angiotensin II receptor type 1 (AGTR1), SMURF2, a gene involved in terminating TGF $\beta$ signalling, NCOR2, a transcriptional co-repressor and BMP4, a member of the TGF $\beta$ family. Compared to untreated samples, we confirmed that TGF $\beta$ upregulated AGTR1 (ratio $=2.4 ; \mathrm{p}=0.002$ ), SMURF2, $($ ratio $=1.8, \mathrm{p}=0.003)$, NCOR2 (ratio $1.4 ; \mathrm{p}=$ 0.004 ), and downregulated BMP4 (ratio $=0.4 ; \mathrm{p}=0.009$ ), with no difference in the response between control and fibrotic fibroblasts (Figure 1).

\section{Induction of angiotensin II receptor type I by TGF $\beta$}

We focused on AGTR1 protein because, as shown by microarray analysis, it was the most highly TGF $\beta$-induced gene among signaling molecules in both control and fibrotic fibroblasts (Table 2). To verify whether AGTR1 mRNA upregulation corresponded to an increase in protein levels, we performed Western analysis on primary human adult lung fibroblasts exposed to TGF $\beta$ or medium alone in serum-free conditions for 24 hours. The intensity of the angiotensin II receptor 1 immunoreactive band was significantly increased in TGF $\beta$-treated fibroblasts compared to those treated with medium alone $(2.4$ fold; $\mathrm{p}<$
0.001) (Figure 2). To identify the signalling pathways through which TGF $\beta$ induces AGTR1, we evaluated whether the ability of TGF $\beta$ to induce AGTR1 expression in lung fibroblasts was blocked by specific signaling pathway inhibitors. A 30 minute preincubation with the dual MKK1/MKK2 inhibitor U0126 significantly inhibited TGF $\beta$ induction of AGTR1 protein ( $\mathrm{p}<0.01)$, whereas predominant MKK1 inhibitor PD98059 and p38 MAPK inhibitor SB202190 had no significant effect (Figure 2).

\section{AGTRI expression in idiopathic pulmonary fibrosis lung biopsies}

We assessed staining for AGTR1 in lung biopsies from four patients with idiopathic pulmonary fibrosis and compared it to that of three control lungs. In particular we aimed to evaluate AGTR1 staining in fibroblastic foci, aggregates of fibroblasts/myofibroblasts in close contact with alveolar epithelial cells. Both in control and in idiopathic pulmonary fibrosis lung biopsies, AGTR1 immunoreactivity was observed in alveolar epithelial cells and alveolar macrophages. In addition, the fibroblasts within the fibroblastic foci present in idiopathic pulmonary fibrosis biopsies stained positive for the receptor (Figure 3).

\section{Discussion}

In this study we report, for the first time, the transcriptional profile in response to TGF $\beta$ in adult primary human lung fibroblasts both from control and from fibrotic lungs. Our analysis of the response to TGF $\beta$ focused on TGF $\beta$ gene targets involved in transcription and signalling, identifying a series of genes previously unknown to respond to TGF $\beta$ in lung fibroblasts. These included angiotensin II receptor 1, providing further insights into links between TGF $\beta$ and angiotensin in the pathogenesis of fibrosis [31,32].

Although gene expression profiling in response to TGF $\beta$ has been investigated previously, earlier work has been confined to skin fibroblasts [17], keratinocytes [16], and a human fetal lung cell line [18], which is likely to respond differently to TGF $\beta$ from the adult lung fibroblast. Our data cannot be directly compared with the fetal lung fibroblast profiling because of methodological disparities, chiefly due to differences in the timing of the RNA collection. However, even restricting the comparison to results obtained at similar time points, we found a significant dissimilarity. Among transcription factors, only JUNB and TCF8 were upregulated by TGF $\beta$ both in fetal [18] and in adult lung fibroblasts, while all others differed between the two cell types. Interestingly, in this study, TGF $\beta$ caused an induction of both MKL1 and serum response factor, while neither were upregulated in fetal lung fibroblasts. The recently reported cooperation between these two transcription factors in determining smooth muscle cell 


\section{Angiotensin II receptor I}
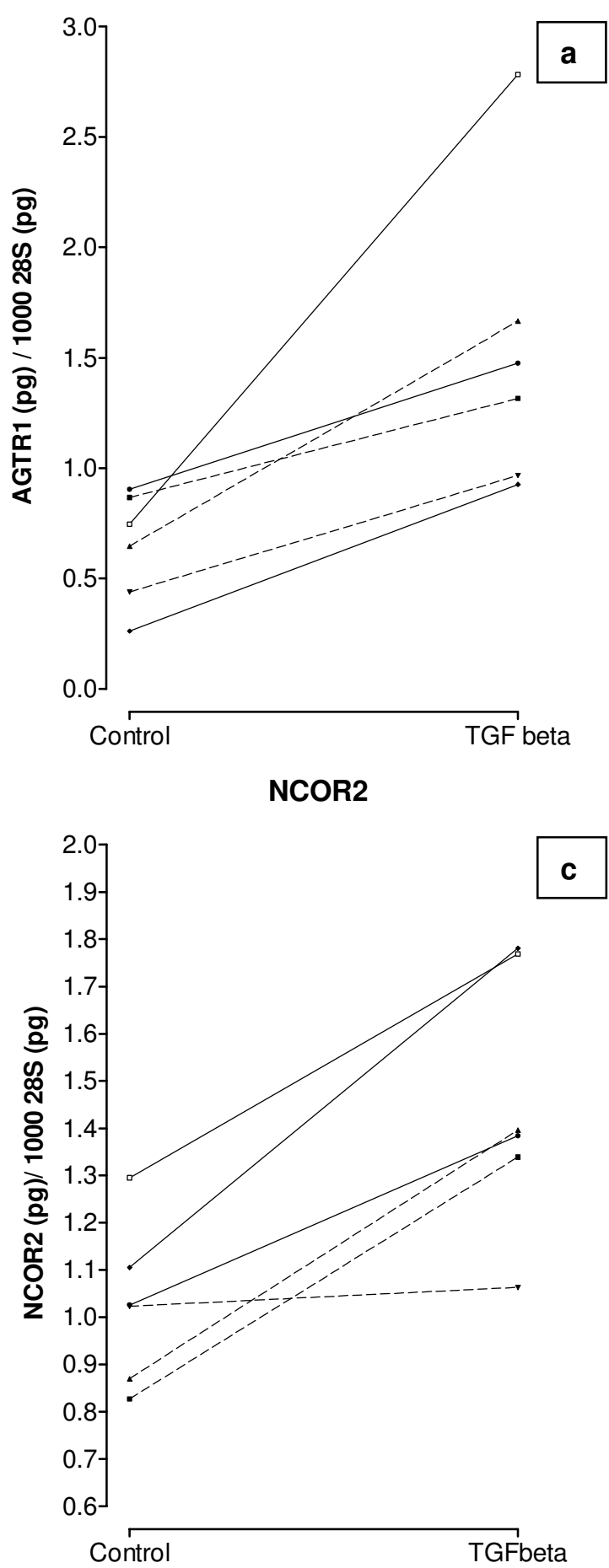

BMP 4

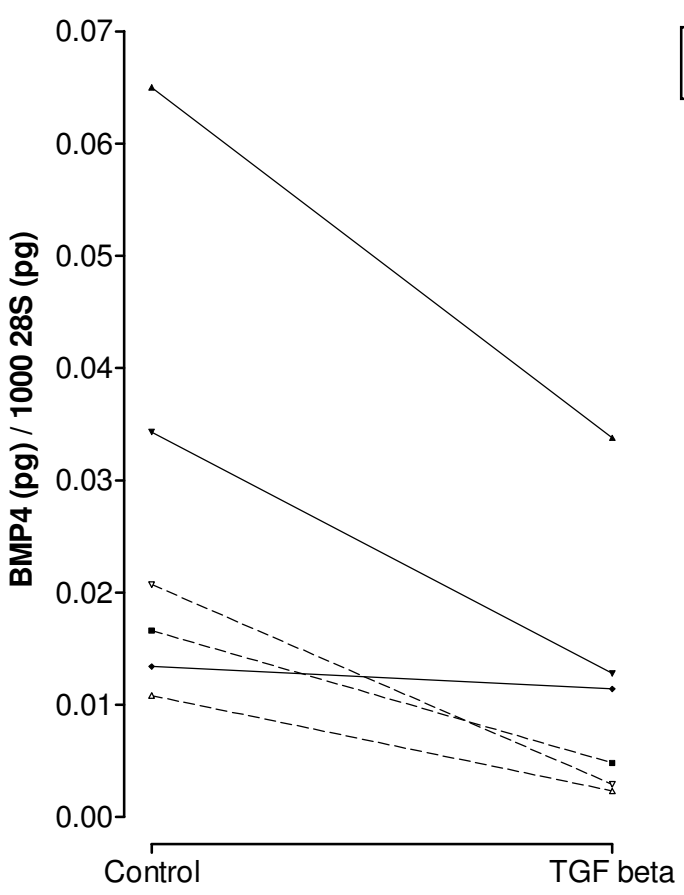

SMURF2

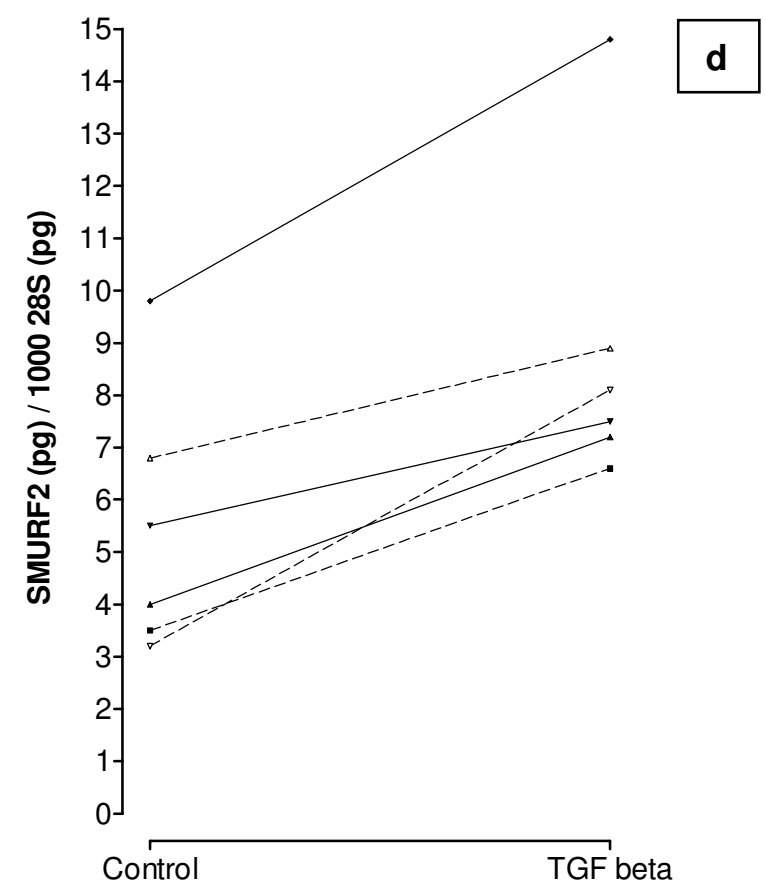

Figure I

Independent verification of microarray results by measurement of gene expression with real time-PCR. TGF $\beta$ treatment $(4 \mathrm{ng} / \mathrm{ml})$ for four hours induces expression of mRNA for angiotensin receptor I (panel a), nuclear receptor co-repressor 2 (NCOR2) (panel c) and SMURF2 (panel d) as well as inhibition of bone morphogenetic protein 4 (panel b) in three control lung fibroblast cell lines (dashed lines) and three fibrotic lung fibroblasts (solid lines). 


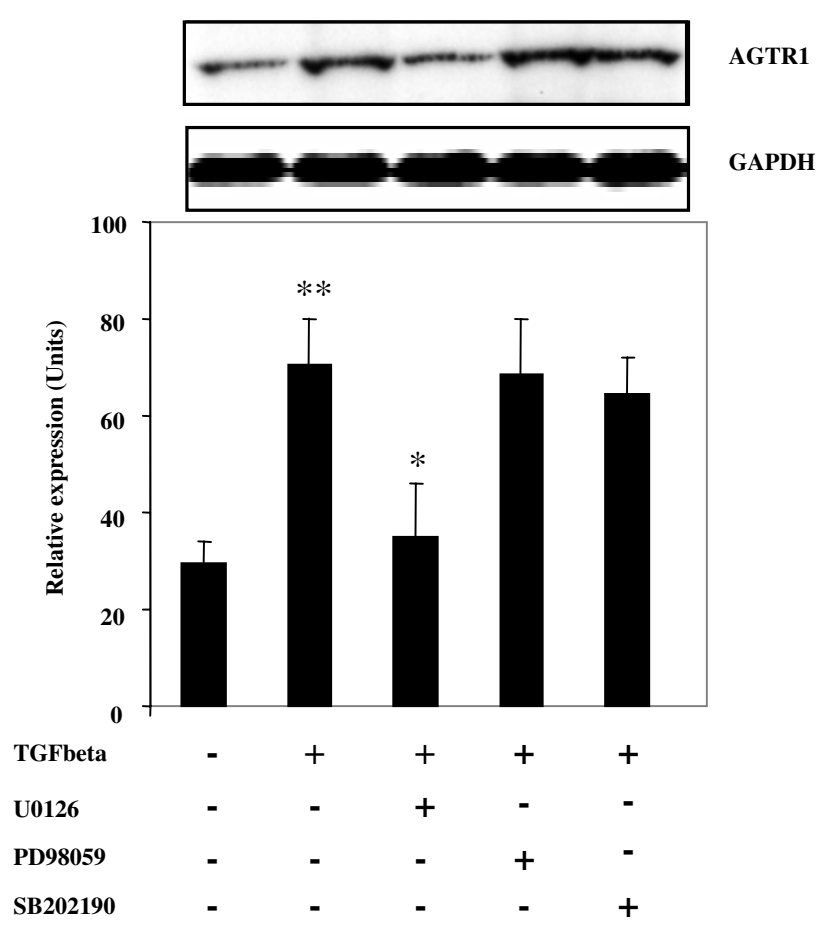

Figure 2

TGF $\beta$ treatment induces angiotensin II receptor I (AGTRI) protein expression in adult lung fibroblasts; the induction is mediated by MKKIIMKK2. Representative Western Blot (top) and average values $( \pm S D)$ of angiotensin II receptor type I protein expression in lung fibroblasts treated with TGF $\beta$ (4 ng/ $\mathrm{ml}$ )with or without I/2 hour pre-incubation with of one the following signalling inhibitors: U0 126, PD98059, SB202190. A 24 hour treatment with TGF $\beta$ induced an upregulation of AGTRI protein (mean: 2.4 fold, ${ }^{*} p<0.001$, Student's paired t-test). The induction of AGTRI by TGF $\beta$ was specifically blocked by MKKI/MKK2 inhibitor UI026 (*p < 0.01 compared with TGF $\beta$-induced AGTRI, Student's paired t-test), but not by predominant MKKI inhibitor PD98059 or p38 inhibitor SB202190). The results are representative of three independent experiments on both control and fibrotic cell lines. As a loading control, Western analysis with an antiGAPDH antibody was also performed.

differentiation [33] suggests that they may play a similar role in lung fibroblasts and suggests differences between fetal and adult lung fibroblasts in the transcriptional programs involved in the TGF $\beta$-induced acquisition of the myofibroblastic phenotype.

In this study, we did not observe a substantial difference in the response to TGF $\beta$ between lung fibroblasts from two patterns of fibrotic lung disease and control lung fibroblasts. In vivo heterogeneity between interstitial lung fibroblasts may occur in fibrotic and normal lung, obscuring the demarcation between normal and abnormal phenotypes, when cell lines are isolated using standard techniques [34,35]. This may explain discrepancies among studies on growth rate and resistance to apoptosis in fibroblasts derived from fibrotic lungs [34,36]. In particular, the fibroblasts/myofibroblasts forming the fibroblastic foci, observed to be linked to disease progression [37], could differ from the remaining fibroblasts found in the interstitium. The issue of sampling a population of homogeneous lung fibroblasts will be the subject of further investigation by using laser microdissection techniques targeting fibroblastic foci coupled with new technologies to amplify RNA from limited quantities of tissue [38]. Further, it is possible that the absence of striking differences in the response to TGF $\beta$ between disease groups and controls is due to a loss of the pro-fibrotic phenotype in vitro, even though the gene expression patterns of different passages of the same fibroblast line have been observed to cluster together, indicating that the in vitro phenotypes are stable through several passages in culture [19]. Further, we ensured that RNA was extracted from all fibroblast lines at comparable passages. Thus, even though our study cannot exclude the presence of subtle differences in the response to TGF $\beta$, we have observed that, overall, fibrotic lung fibroblasts retain the capacity to respond to TGF $\beta$, which could therefore be targeted by pharmacological means.

Among the novel TGF $\beta$ targets identified by microarray analysis in lung fibroblasts, we focused our attention on the induction of angiotensin II receptor type 1 (AGTR1), as its involvement is likely to significantly amplify the profibrotic actions of TGF $\beta$. The ligand for this receptor is angiotensin II, a vasoactive peptide which has been linked to fibrogenesis in the kidney and in the heart $[39,40]$. Recent studies have indicated that a local renin-angiotensin system could also be involved in the development of lung fibrosis $[41,42]$. Elevated angiotensin converting enzyme levels have been found in bronchoalveolar lavage (BAL) fluid from patients with idiopathic pulmonary fibrosis [41]. Compared to controls, lung fibroblasts from patients with idiopathic pulmonary fibrosis produce higher levels of angiotensin II, shown to induce apoptosis in alveolar epithelial cells through AGTR1 [31,43]. Blockade of angiotensin II or of AGTR1 attenuates lung collagen deposition in animal models of lung fibrosis [42,32]. Interestingly, the modulation of AGTR1 could be cell specific, as suggested by the report that TGF $\beta$ reduces AGTR1 expression in cardiac fibroblasts [44].

In addition to Smad molecules, the classic signalling pathway used by TGF $\beta$ family members, TGF $\beta$ also signals through the mitogen-activated protein kinase (MAPK) signalling pathways [16]. In this study, TGF $\beta$ was found to 


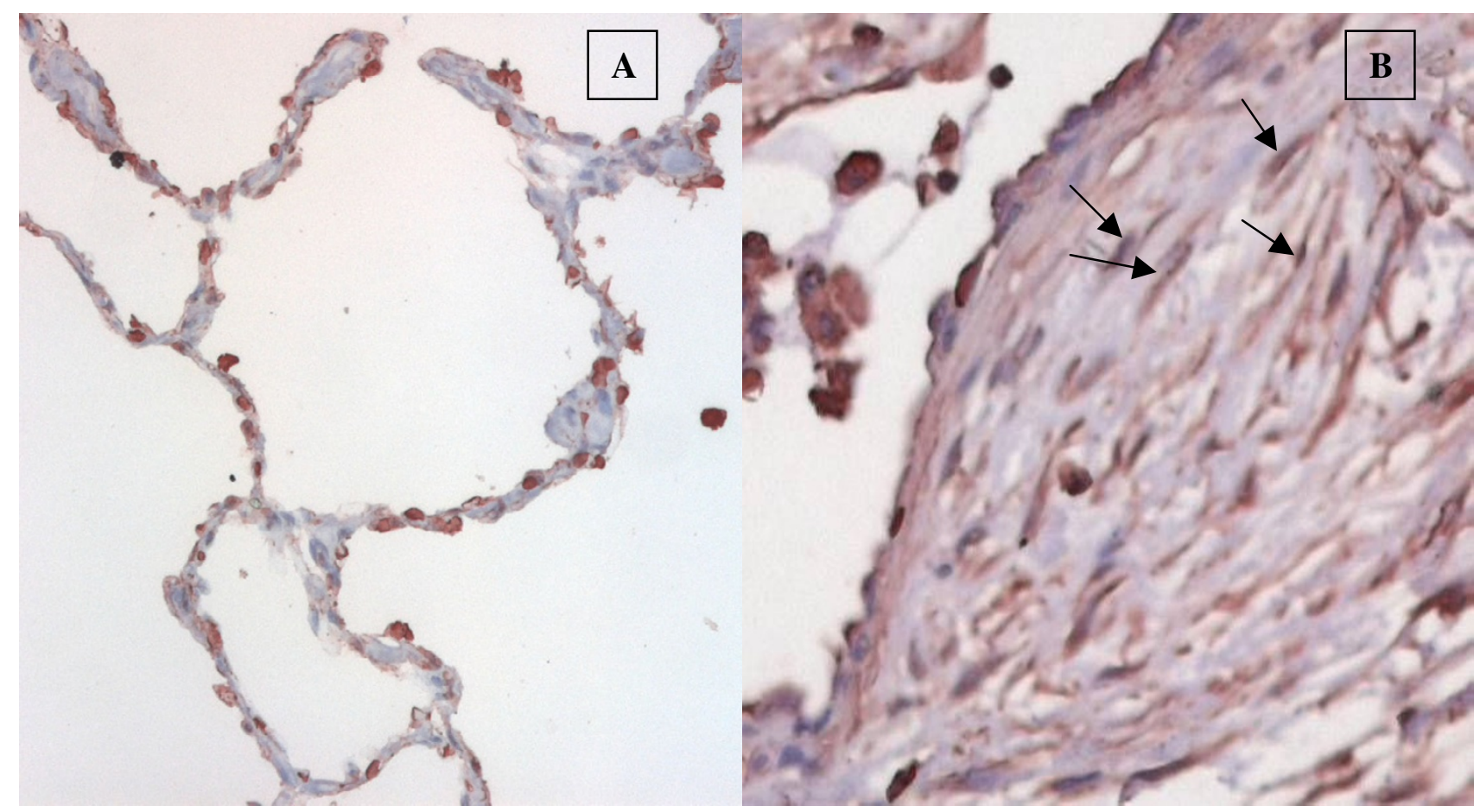

\section{Figure 3}

Angiotensin II receptor I staining in lung biopsies from control patients (A) and from patients with idiopathic pulmonary fibrosis (B). Immunohistochemistry for the angiotensin II receptor I (AGTRI), counterstained with haematoxylin. AGTRI positive staining is seen in alveolar macrophages, in epithelial cells and in fibroblastic foci (arrows) in usual interstitial pneumonia biopsies (panel B). Epithelial cells and alveolar macrophages express AGTRI in control lung biopsies (panel A).

induce AGTR1 via mitogen-activated protein kinase kinase (MKK1/MKK2). The finding that the MKK1/MKK2 inhibitor U0126, but not the MKK1 inhibitor PD98059, was able to suppress TGF $\beta$-induced AGTR1 expression, suggests that both MKK1 and MKK2 must be antagonized in order to inhibit transcription.

The functional effects of AGTR1 stimulation in lung fibroblasts are only partially known. Although two isoforms of angiotensin II receptor exist, AGTR1 and AGTR2, the effects described so far of angiotensin II on lung fibroblasts are ascribed to the type 1 receptor. AGTR1 has been found to mediate mitogenesis in human lung fibroblasts [45] and extracellular matrix synthesis in lung [46] as well as in cardiac and dermal fibroblasts [47]. Whereas angiotensin II is known to induce TGF $\beta$ [46], the regulation of AGTR1 by TGF $\beta$ has not, to our knowledge, been previously reported in lung fibroblasts. Our data support the concept of a positive feed back loop by which TGF $\beta$ potentiates the pro-fibrotic actions of angiotensin II by increasing AGTR1 expression, providing a mechanism for the attenuation of the proliferative response to angi- otensin II by TGF $\beta$ blockade [45]. Thus, cooperation and amplification of pro-fibrotic effects between TGF $\beta$ and AGTR1 are likely to be implicated in lung fibrosis. Interestingly, adrenomedullin, a multifunctional vasodilatory peptide that downregulates angiotensin II-induced collagen biosynthesis in cardiac fibroblasts [48], was inhibited by TGF $\beta$, confirming a previous report [49], and suggesting that TGF $\beta$ exerts a complex regulation over vasoactive peptides and/or their receptors in lung fibroblasts.

AGTR1 was found to localize to fibroblasts within fibroblastic foci in IPF/UIP biopsies. An increase in AGTR1 staining has been reported in the fibrotic regions surrounding the bronchioles in chronic obstructive pulmonary disease [50]. The finding that AGTR1 localizes to fibroblastic foci in IPF biopsies supports the potential relevance of the angiotensin system in this disease and suggests that the pro-fibrotic role of AGTR1 in IPF is not limited to epithelial cells [31]. Further studies are needed to assess the functional effects of AGTR1 stimulation in lung fibroblasts and to evaluate the biological role of AGTR1 in lung fibrosis. 


\section{Conclusions}

Our findings confirm that in response to TGF $\beta$, both control and fibrotic lung fibroblasts are potent effector cells expressing a very wide range of genes that are likely to contribute to the fibrotic process. In particular, we have shown that TGF $\beta$ has the capacity to influence the expression of angiotensin II receptor type 1 both at the mRNA and at the protein level. In view of the known induction of TGF $\beta$ by angiotensin II [45], our findings support the existence of a self-potentiating loop between TGF $\beta$ and angiotensin II, resulting in the amplification of the profibrotic effects of both systems. Future treatment strategies could be based on the disruption of such interactions.

\section{Authors' contributions}

EAR participated in the design and interpretation of the study, carried out the cell culture work and participated in the microarray work, performed immunohistochemistry staining, and drafted the manuscript. DJA participated in the design and coordination of the study and in the preparation of the manuscript, SH performed the RT-PCR assays, XSW carried out the Western Blot analysis, PS performed the statistical analysis and participated in the interpretation of results and preparation of the manuscript, GBG participated in the microarray work, AUW participated in the interpretation of results, SV participated in cell line selection and clinical characterization, AGN reviewed fibrotic lung biopsies and interpreted immunohistochemistry staining, CD and CMB contributed towards the overall organizational setup for the study of lung fibroblast lines and participated in the interpretation of results, AL and JDP participated in the preparation of the manuscript, KIW conceived of the study and participated in the design, RdB participated in study design, interpretation and coordination. All authors read and approved the final manuscript.

\section{Additional material}

\section{Additional File 1}

Complete list of genes regulated by a four hour treatment with TGF $\beta$ in control and fibrotic fibroblasts This data set contains all the genes up- or down-regulated by a four hour treatment with TGF $\beta$ (according to the criteria described in the methods) in control and fibrotic lung fibroblasts. Fibrotic lung fibroblast fold ratios are the average of the fold ratios for lung fibroblasts from idiopathic pulmonary fibrosis and pulmonary fibrosis associated with systemic sclerosis. Genes are sub-grouped into functional classes. Affymetrix probe set numbers, approved gene symbols, gene names and GenBank accession numbers are provided in the table.

Click here for file

[http://www.biomedcentral.com/content/supplementary/14659921-5-24-S1.xls]

\section{Acknowledgments}

We are grateful to Helen Causton, Laurence Game, Nicola Cooley and Helen Banks of the CSC/IC Microarray Centre for expert help with Affymetrix microarray experiments. We thank Carmen Fonseca, Paul Beirne and Alan Holmes for their technical expertise and for their review of the manuscript. This work was supported by the Royal Brompton \& Harefield Clinical Research Fund, by the Raynaud's and Scleroderma Association Trust, the Scleroderma Society, the Welton Foundation, the Rosetrees Charitable Trust, and by the Arthritis and Research Council.

\section{References}

I. Sporn MB, Roberts $A B$ : Transforming growth factor beta: recent progress and new challenges. J Cell Biol 1992, I 19:1017-1021.

2. Blobe GC, Schiemann WP, Lodish HF: Role of transforming growth factor beta in human disease. $N$ Engl J Med 2000, 342:1350-8.

3. Broekelmann T, Limper AH, Colby TV, MacDonald JA: Transforming growth factor beta $I$ is present at sites of extracellular matrix gene expression in human pulmonary fibrosis. Proc Natl Acad Sci USA 1991, 88:6642-6646.

4. Giri SN, Hyde DM, Hollinger A: Effect of antibody to transforming growth factor beta on bleomycin induced accumulation of lung collagen in mice. Thorax 1993, 48:959-966.

5. Sime PJ, Xing Z, Graham FL, Csaky KG, Gauldie J: Adenovectormediated gene transfer of active transforming growth factor- betal induces prolonged severe fibrosis in rat lung. J Clin Invest 1997, 100:768-776.

6. Corrin B, Butcher D, McAnulty BJ, Dubois RM, Black CM, Laurent G], Harrison NK: Immunohistochemical localization of transforming growth factor-beta $I$ in the lungs of patients with systemic sclerosis, cryptogenic fibrosing alveolitis and other lung disorders. Histopathology 1994, 24: I45-50.

7. Khalil N, O'Connor RN, Flanders KC, Unruh H: TGF-beta I, but not TGF-beta 2 or TGF-beta 3 , is differentially present in epithelial cells of advanced pulmonary fibrosis: an immunohistochemical study. Am J Respir Cell Mol Biol 1996, 14:131-8.

8. American Thoracic Society/European Respiratory Society International Multidisciplinary Consensus Classification of the Idiopathic Interstitial Pneumonias. Am J Respir Crit Care 2002, 165:277-304.

9. Black CM, du Bois R: Organ involvement: pulmonary. In Systemic sclerosis Edited by: Clements PJ, Furst DE. Baltimore, MD: Williams and Wilkins; 1996:299-331.

10. Munger JS, Huang X, Kawakatsu H, Griffiths MJ, Dalton SL, Wu J, Pittet JF, Kaminski N, Garat C, Matthay MA, Rifkin DB, Sheppard D: The integrin alpha $v$ beta 6 binds and activates latent TGF beta I: a mechanism for regulating pulmonary inflammation and fibrosis. Cell 1999, 96:319-28.

II. Lee CG, Homer RJ, Zhu Z, Lanone S, Wang X, Koteliansky V, Shipley JM, Gotwals P, Noble P, Chen Q, Senior RM, Elias JA: Interleukin13 induces tissue fibrosis by selectively stimulating and activating transforming growth factor $\beta I$. J Exp Med 200I, I94:809-82I.

12. McCormick LL, Zhang Y, Tootell E, Gilliam AC: Anti-TGF-beta treatment prevents skin and lung fibrosis in murine sclerodermatous graft-versus-host disease: a model for human scleroderma. J Immunol 1999, 163:5693-9.

13. Wang Q, Wang Y, Hyde DM, Gotwals PJ, Koteliansky VE, Ryan ST, Giri SN: Reduction of bleomycin induced lung fibrosis by transforming growth factor beta soluble receptor in hamsters. Thorax 1999, 54:805-12.

14. Nakao A, Fujii M, Matsumura R, Kumano K, Saito Y, Miyazono K, Iwamoto I: Transient gene transfer and expression of Smad7 prevents bleomycin-induced lung fibrosis in mice. J Clin Invest 1999, 104:5-II.

15. Selman M, King TE, Pardo A: Idiopathic pulmonary fibrosis: prevailing and evolving hypotheses about its pathogenesis and implications for therapy. Ann Intern Med 200I, 134:I36-15II5.

16. Zavadil J, Bitzer M, Liang D, Yang YC, Massimi A, Kneitz S, Piek E, Bottinger EP: Genetic programs of epithelial cell plasticity directed by transforming growth factor-beta. Proc Natl Acad Sci U S A 200I, 98:6686-9I. 
17. Verrecchia F, Chu ML, Mauviel A: Identification of novel TGFbeta /Smad gene targets in dermal fibroblasts using a combined CDNA microarray/promoter transactivation approach. J Biol Chem 200I, 276: I7058-62.

18. Chambers RC, Leoni P, Kaminski N, Laurent GJ, Heller RA: Global expression profiling of fibroblast responses to transforming growth factor-betal reveals the induction of inhibitor of differentiation-I and provides evidence of smooth muscle cell phenotypic switching. Am J Pathol 2003, 162:533-46.

19. Chang HY, Chi JT, Dudoit S, Bondre C, van de Rijn M, Botstein D, Brown PO: Diversity, topographic differentiation, and positional memory in human fibroblasts. Proc Natl Acad Sci U S A 2002, 99: I 2877-82.

20. Shi-wen $X$, Pennington $D$, Holmes A, Leask A, Bradham D, Beauchamp JR, Fonseca C, du Bois RM, Martin GR, Black CM, Abraham DJ: Autocrine overexpression of CTGF maintains fibrosis: RDA analysis of fibrosis genes in systemic sclerosis. Exp Cell Res 2000, 259:2। 3-24.

21. Alessi DR, Cuenda A, Cohen P, Dudley DT, Saltiel AR: PD 098059 is a specific inhibitor of the activation of mitogen-activated protein kinase kinase in vitro and in vivo. J Biol Chem 1995, 270:27489-94.

22. Zaidi SK, Sullivan AJ, Van Wijnen AJ, Stein JL, Stein GS, Lian JB: Integration of Runx and Smad regulatory signals at transcriptionally active subnuclear sites. Proc Natl Acad Sci USA 2002, 99:8048-8053.

23. Adya N, Castilla LH, Liu PP: Function of CBFbeta/Bro proteins. Semin Cell Dev Biol 2000, I I:361-368.

24. Stroschein SL, Bonni S, Wrana JL, Luo K: Smad3 recruits the anaphase-promoting complex for ubiquitination and degradation of SnoN. Genes Dev 200I, I 5:2822-36.

25. Shi $Y$, Downes $M, X i e ~ W, K a o$ HY, Ordentlich P, Tsai CC, Hon M, Evans RM: Sharp, an inducible cofactor that integrates nuclear receptor repression and activation. Genes Dev 200I, 15:I| $40-5 \mid$.

26. Abreu JG, Ketpura NI, Reversade B, De Robertis EM: Connectivetissue growth factor (CTGF) modulates cell signalling by BMP and TGF-beta. Nat Cell Biol 2002, 4:599-604

27. Kavsak P, Rasmussen RK, Causing CG, Bonni S, Zhu H, Thomsen GH, Wrana JL: Smad7 binds to Smurf2 to form an E3 ubiquitin ligase that targets the TGF beta receptor for degradation. Mol Cell 2000, 6: $1365-75$

28. Lin X, Liang M, Feng XH: Smurf2 is a ubiquitin E3 ligase mediating proteasome-dependent degradation of Smad2 in transforming growth factor-beta signaling. I Biol Chem 2000, 275:368|8-22

29. Ohga E, Matsuse T, Teramoto S, Ouchi Y: Activin receptors are expressed on human lung fibroblast and activin $A$ facilitates fibroblast-mediated collagen gel contraction. Life Sci 2000, 66:1603-13.

30. Kaminski N, Allard JD, Pittet JF, Zuo F, Griffiths MJ, Morris D, Huang $X$, Sheppard D, Heller RA: Global analysis of gene expression in pulmonary fibrosis reveals distinct programs regulating lung inflammation and fibrosis. Proc Natl Acad Sci U S A 2000, 97:1778-83

31. Papp M, Li X, Zhuang J, Wang R, Uhal BD: Angiotensin receptor subtype AT(I) mediates alveolar epithelial cell apoptosis in response to ANG II. Am J Physiol Lung Cell Mol Physiol 2002, 282:L7|3-8.

32. Otsuka M, Takahashi H, Shiratori M, Chiba H, Abe S: Reduction of bleomycin induced lung fibrosis by candesartan cilexetil, an angiotensin II type I receptor antagonist. Thorax 2004, 59:3 I-8.

33. Du KL, Chen M, Li J, Lepore JJ, Mericko P, Parmacek MS: Megakaryoblastic leukemia factor-I transduces cytoskeletal signals and induces smooth muscle cell differentiation from undifferentiated embryonic stem cells. J Biol Chem 2004, 279: 17578-86

34. Jordana M, Schulman J, McSharry C, Irving LB, Newhouse MT, Jordana G, Gauldie J: Heterogeneous proliferative characteristics of human adult lung fibroblast lines and clonally derived fibroblasts from control and fibrotic tissue. Am Rev Respir Dis 1998, 37:579-84.

35. Uhal BD, Ramos C, Joshi I, Bifero A, Pardo A, Selman M: Cell size, cell cycle, and alpha-smooth muscle actin expression by primary human lung fibroblasts. Am J Physiol I998, 275:L998-LI 005.
36. Ramos C, Montano M, Garcia-Alvarez J, Ruiz V, Uhal BD, Selman M, Pardo A: Fibroblasts from idiopathic pulmonary fibrosis and normal lungs differ in growth rate, apoptosis, and tissue inhibitor of metalloproteinases expression. Am J Respir Cell Mol Biol 200I, 24:59I-8.

37. King TE Jr, Schwarz MI, Brown K, Tooze JA, Colby TV, Waldron JA Jr, Flint A, Thurlbeck W, Cherniack RM: Idiopathic pulmonary fibrosis: relationship between histopathologic features and mortality. Am J Respir Crit Care Med 200I, 164:1025-32.

38. Mahadevappa $M$, Warrington JA: A high-density probe array sample preparation method using 10 - to 100 -fold fewer cells. Nat Biotechnol 1999, 7:1 134-6.

39. Klahr S, Morrissey J: Obstructive nephropathy and renal fibrosis. Am J Physiol Renal Physiol 2002, 283:F86I-F875.

40. Gonzalez A, Lopez B, Diez J: Fibrosis in hypertensive heart disease: role of the renin-angiotensin-aldosterone system. Med Clin North Am 2004, 88:83-97.

4I. Specks U, Martin WJ 2nd, Rohrbach MS: Bronchoalveolar lavage fluid angiotensin-converting enzyme in interstitial lung diseases. Am Rev Respir Dis I 4 I:I I 7-23.

42. Wang R, Ibarra-Sunga O, Verlinski L, Pick R, Uhal BD: Abrogation of bleomycin-induced epithelial apoptosis and lung fibrosis by captopril or by a caspase inhibitor. Am J Physiol Lung Cell Mol Physiol 2000, 279:LI 43-5I.

43. Uhal BD, Joshi I, Hughes WF, Ramos C, Pardo A, Selman M: Alveolar epithelial cell death adjacent to underlying myofibroblasts in advanced fibrotic human lung. Am J Physiol 1998, 275:LI I92-9.

44. Gurantz D, Cowling RT, Villarreal FJ, Greenberg BH: Tumor necrosis factor-alpha upregulates angiotensin II type I receptors on cardiac fibroblasts. Circ Res 1999, 85:272-9.

45. Marshall RP, McAnulty RJ, Laurent G]: Angiotensin II is mitogenic for human lung fibroblasts via activation of the type I receptor. Am J Respir Crit Care Med 2000, 161:1999-2004.

46. Marshall RP, Gohlke P, Chambers RC, Howell DC, Bottoms S, Unger T, McAnulty RJ, Laurent GJ: Angiotensin II and the Fibroproliferative Response to Acute Lung Injury. Am J Physiol Lung Cell Mol Physiol 2004, 286:LI56-LI64.

47. Crabos M, Roth M, Hahn AW, Erne P: Characterization of angiotensin II receptors in cultured adult rat cardiac fibroblasts. Coupling to signaling systems and gene expression. J Clin Invest 1994, 93:2372-2378.

48. Autelitano DJ, Ridings R, Pipolo L, Thomas WG: Adrenomedullin inhibits angiotensin ATIA receptor expression and function in cardiac fibroblasts. Regul Pept 2003, I I 2:13 I-7.

49. Isumi Y, Minamino N, Katafuchi T, Yoshioka M, Tsuji T, Kangawa K, Matsuo $\mathrm{H}$ : Adrenomedullin production in fibroblasts: its possible function as a growth regulator of Swiss 3T3 cells. Endocrinology 1998, 139:2552-63.

50. Bullock GR, Steyaert I, Bilbe G, Carey RM, Kips J, De Paepe B, Pauwels R, Paet M, Siragy HM, de Gasparo M: Distribution of type-I and type-2 angiotensin receptors in the normal human lung and in lungs from patients with chronic obstructive pulmonary disease. Histochem Cell Biol 200 I, I I 5: I 17-24.

Publish with Bio Med Central and every scientist can read your work free of charge

"BioMed Central will be the most significant development for disseminating the results of biomedical research in our lifetime. "

Sir Paul Nurse, Cancer Research UK

Your research papers will be:

- available free of charge to the entire biomedical community

- peer reviewed and published immediately upon acceptance

- cited in PubMed and archived on PubMed Central

- yours - you keep the copyright
BioMedcentral 